\title{
Effect of Hydroxyl-Terminated Random Copolyether (PET) and Hydroxyl-Terminated Polybutadiene (HTPB) on Thermal Decomposition Characteristics of Ammonium Perchlorate
}

\author{
Ke-Zhu Mao, Min Xia and Yun-Jun Luo*
}

\author{
School of Materials Science and Engineering, Beijing Institute of Technology, Beijing 100081, China
}

\begin{abstract}
The effects of two binders (PET and HTPB) on thermal decomposition characteristics of Ammonium Perchlorate were studied by TG-FTIR, DSC and SEM. When Hydroxyl-terminated polybutadiene (HTPB) mixes with AP, there is no obvious mutual effect in the process of heating, but it happen in the other way when Hydroxyl-terminated random copolyether (PET) mixes with AP. During the heating process of PET-AP mixture, the decomposition of PET occur in advance significantly, so that the porous structure of AP at the low-temperature decomposition stage becomes more significant, the total amount of heat released increases significantly, and the weight-loss ratio of AP about the two stages increases to about 2:1. During the thermal decomposition, the heat release and $\mathrm{N}_{2} \mathrm{O}$ gas production of PET-AP mixture is milder than the HTPB-AP, which is more conducive to the insensitive properties of propellant.
\end{abstract}

Keywords: Insensitive propellant, TGA-FTIR, Thermal Decomposition characteristics, porous structure, $\mathrm{N}_{2} \mathrm{O}$.

\section{INTRODUCTION}

Ammonium perchlorate (AP) is widely used as an oxidizer in composite solid propellants because of the excellent performance (high oxygen content, high density, high specific volume of combustion product, good stability for storage and use, low price, etc.), and its content is about $60 \% \sim 75 \%$ by weight. Therefore, various properties of propellant are strongly dependent on the characteristics of AP, such as the characteristics of thermal decomposition, burning behavior, and insensitive property. Hence, the research onthe effect of other components of propellant on the thermal decomposition characteristics of AP is very important $[1,2]$.

The binder is a liquid pre-polymer with active functional groups, which is known as the elastic matrix of propellant, to provide a certain mechanical properties for the propellant. But it is also a certain energy fuel, and thermal decomposition and release of energy will happen in the heating process, then it will interact with other components of the propellant during the thermal decomposition and combusition [3, 4].

As we know, the HTPB propellant is not insensitive during the sensitivity tests, especially the slow cook-off test. On the other hand, the PET based propellant can pass all of the sensitivity tests. Many researchers consider the high solid content as main problem of HTPB propellant, but there may be another reason, which is the interaction between binders and AP.

*Address correspondence to this author at the School of Materials Science and Engineering, Beijing Institute of Technology, Beijing 100081, China; E-mail: yjluo@bit.edu.cn
Many researchers have intensively investigated the thermal decomposition characteristics of AP in the presence of other substances, including a variety of catalysts [5-10], high explosives [11-13], aluminum powder and nano-composite particles [14-16], and so on. But as far as we know, there is no report about the interaction between PET and AP.

Hence, in this paper, the thermal decomposition characteristics of two binders (HTPB and PET, AP, HTPB-AP mixture and PET-AP mixture were studied by TG-FTIR, DSC test methods, and the interaction between the binders and AP were analyzed. The surface morphology of AP before and after the lowtemperature decomposition stage was observed by SEM, to analyze the difference of two binders on interaction with AP. This research can provide a theoretical basis for the further understanding and research of insensitive propellant.

\section{EXPERIMENTAL SECTION}

\subsection{Materials}

Hydroxyl-terminated random copolyether (PET, $M_{n}=4038$ ) and Hydroxyl-terminated polybutadiene (HTPB, $M_{n}=3020$ ) were purchased in Liming Research Institute of Chemical Industry; $\operatorname{AP}(200 \sim 300 \mu \mathrm{m})$ was obtained from Dalian factory of potassium chlorate.

\subsection{Analysis}

TG-FTIR (METTLER TOLEDO TG/DSC 1, Thermo Nicolet IS10) was used in TG/DSC experiments, the samples weighing about $3 \mathrm{mg}$ were heated at a rate of $10 \mathrm{~K} \cdot \mathrm{min}^{-1}$ from 30 to $600^{\circ} \mathrm{C}$ under a static atmosphere 
of nitrogen (the flow rate is $40 \mathrm{~mL} \cdot \mathrm{min}^{-1}$ ). The temperature of gas product connecting pipe between the thermal analysis equipment and infrared spectrometer is $220^{\circ} \mathrm{C}$, the temperature of infrared gas pool in situ is $230^{\circ} \mathrm{C}$, and the ir detector is DTGS $\mathrm{KBr}$, whose resolution is $4 \mathrm{~cm}^{-1}$.

The separate DSC measurements were performed using SHIMADZUDSC1/500/578. The samples (5-10 $\mathrm{mg}$ ) were heated at a rate of $10 \mathrm{~K} \cdot \mathrm{min}^{-1}$ in specific pans from 30 to $600^{\circ} \mathrm{C}$ under a static atmosphere of nitrogen at $40 \mathrm{~mL} \cdot \mathrm{min}^{-1}$.

The SEM analyses were performed using the TM3000 scanning electron microscope.

\section{RESULTS \& DISCUSSION}

\subsection{TG-FTIR}

\subsubsection{The Interaction between HTPB and AP during the Heating}

As we know, the HTPB propellant is not insensitive, and many researchers consider the high solid content as main problem. But there may be another reason, which is the interaction between HTPB and AP.

In order to study the effect of HTPB on thermal decomposition of AP, the HTPB prepolymer and AP crystals were mixed in a mass ratio of $1: 1$, then the thermal decomposition behavior of AP, HTPB prepolymer, and the mixture was studied. The TG/DTG curves of AP, HTPB, and HTPB-AP mixture are given in Figure 1, and their characteristic parameters are listed in Table 1.

According to the results in Table 1, there are two weightlessness stages during the thermal decomposition of AP, corresponding to the lowtemperature decomposition stage and hightemperature decomposition stage, and the mass loss ratio of two stages is about 3:7. Furthermore, the interval of two peaks is $90{ }^{\circ} \mathrm{C}$. The thermal decomposition process of HTPB also have two weight loss stages, but the thermal weight loss of HTPB-AP mixture is divided into three stages, which may be because the high-temperature decomposition stage of $\mathrm{AP}$ and the low-temperature decomposition stage of HTPB happen concurrently.

The gas products infrared spectrograms of HTPBAP mixture during the thermal decomposition at different temperature are given in Figure 2. The characteristic absorption peaks of $\mathrm{N}_{2} \mathrm{O}\left(2201 \sim 2238 \mathrm{~cm}^{-}\right.$ $\left.1,1250 \sim 1300 \mathrm{~cm}^{-1}\right)$ and $\mathrm{HCl}\left(2700 \sim 3012 \mathrm{~cm}^{-1}\right)$ can be found during the first decomposition stage, indicating that this stage is mainly the low-temperature

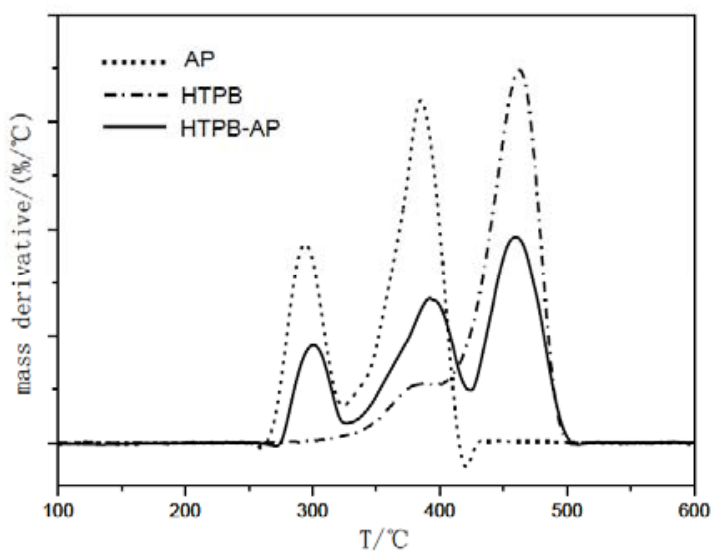

Figure 1: TG/DTG curves of AP, HTPB, HTPB-AP.

Table 1: TG/DTG Characteristic Values of AP, HTPB, HTPB-AP

\begin{tabular}{|c|c|c|c|c|c|c|c|c|c|}
\hline \multirow[b]{2}{*}{ Samples } & \multicolumn{3}{|c|}{ First Stage } & \multicolumn{3}{|c|}{ Second Stage } & \multicolumn{3}{|c|}{ Third Stage } \\
\hline & $\mathrm{T}_{1} /{ }^{\circ} \mathrm{C}$ & $\begin{array}{c}\text { Mass } \\
\text { Loss } / \%\end{array}$ & $\mathbf{T}_{\mathrm{p} 1} /{ }^{\circ} \mathbf{C}$ & $\mathbf{T}_{2} /{ }^{\circ} \mathbf{C}$ & $\begin{array}{c}\text { Mass } \\
\text { Loss } / \%\end{array}$ & $\mathbf{T}_{\mathrm{p} 2} /{ }^{\circ} \mathbf{C}$ & $\mathrm{T}_{3} /{ }^{\circ} \mathrm{C}$ & $\begin{array}{c}\text { Mass } \\
\text { Loss } / \%\end{array}$ & $\mathbf{T}_{\mathrm{p} 3} /{ }^{\circ} \mathbf{C}$ \\
\hline HTPB & $361.0 \sim 394.7$ & 13.40 & 388.5 & $394.7 \sim 503.6$ & 85.41 & 462.8 & - & - & - \\
\hline HTPB-AP & $296.0 \sim 326.5$ & 13.95 & 300.7 & $326.5 \sim 424.6$ & 37.72 & 392.4 & $424.6 \sim 510.0$ & 43.93 & 458.8 \\
\hline
\end{tabular}






Figure 2: FTIR curves of HTPB-AP mixture at various temperatures.

decomposition stage of AP [11]. The peaks of $\mathrm{N}_{2} \mathrm{O}$ and $\mathrm{HCl}$ remain during the second stage, but the intensity get weaker, and the faint $\mathrm{C}-\mathrm{H}$ stretching vibration peak (2850 3000 $\mathrm{cm}^{-1}$ ) appears. It suggests that the second stage is mainly the high-temperature decomposition of AP, accompanied by a small fraction of the lowtemperature thermal decomposition of HTPB. The characteristic absorption peaks of $\mathrm{C}-\mathrm{H}$ stretching vibration (2850 3000 $\mathrm{cm}^{-1}$ ) and $\mathrm{C}-\mathrm{H}$ in-plane bending vibration $\left(1350 \sim 1490 \mathrm{~cm}^{-1}\right)$ are detected during the

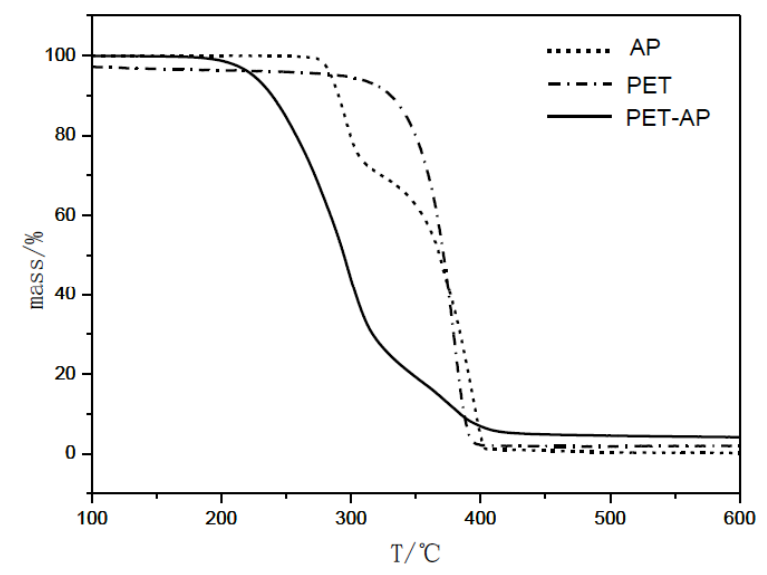

third stage, which means the decomposition reaction of HTPB occurs in this stage mainly.

The thermal decomposition behaviors of HTPB and AP during the heating process of HTPB-AP mixture have no obvious difference with their own thermal decomposition reaction steps respectively. The mass loss ratio of two stages about AP still close to $3: 7$, and the interval of two peaks about AP is $91.7^{\circ} \mathrm{C}$, be very close to that of pure AP. Therefore, HTPB has no obvious influence on the thermal decomposition behavior of AP according to the TG-FTIR analyses.

\subsubsection{The Interaction between PET and AP during the Heating}

The effect of PET on thermal decomposition of AP was studied in the same way. The TG/DTG curves of AP, PET, PET-AP mixture are given in Figure 3, and their characteristic parameters are listed in Table 2. It shows that the thermal weight loss of PET has only one stage, and that of PET-AP mixture has two stages. But the mass loss ratio of two stages increases from 3:7 (pure AP) to about 5:1, which may be because the thermal decomposition of PET occurs ahead and overlapped with low -temperature stage of AP.

The infrared spectra of gas products of PET-AP mixture during the thermal decomposition at various temperatures are given in Figure 4. The characteristic

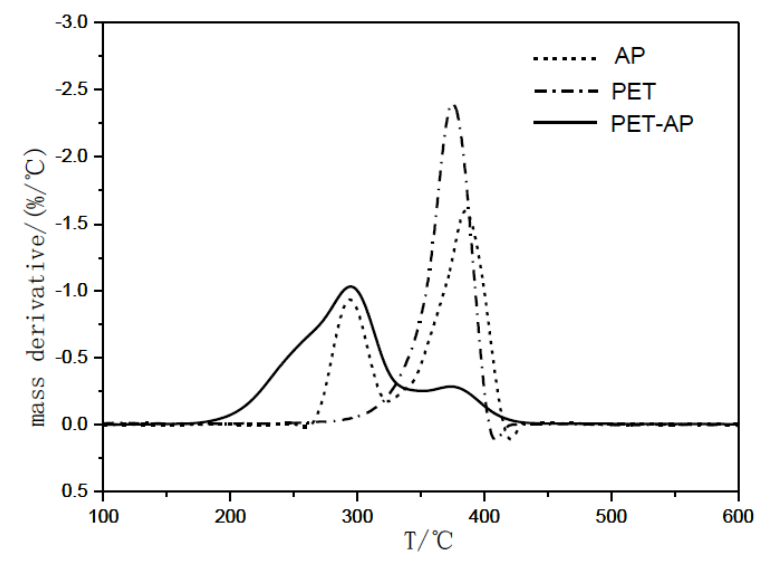

Figure 3: TG/DTG curves of AP, PET, PET-AP.

Table 2: TG/DTG Characteristic Values of AP, PET, PET-AP

\begin{tabular}{|c|c|c|c|c|c|c|}
\hline \multirow{2}{*}{ Samples } & \multicolumn{3}{|c|}{ First Stage } & \multicolumn{3}{c|}{ Second Stage } \\
\cline { 2 - 7 } & $\mathbf{T}_{1} /{ }^{\circ} \mathbf{C}$ & Mass Loss $/ \%$ & $\mathbf{T}_{\mathbf{p} 1} /{ }^{\circ} \mathbf{C}$ & $\mathbf{T}_{2} /{ }^{\circ} \mathbf{C}$ & $\mathbf{M a s s}_{\text {Loss } / \%}$ & $\mathbf{T}_{\mathbf{p} 2} /{ }^{\circ} \mathbf{C}$ \\
\hline \hline AP & $284.0 \sim 324.0$ & 30.00 & 294.0 & $324.0 \sim 420.0$ & 69.00 & 385.0 \\
\hline PET & $291.0 \sim 410.0$ & 99.80 & 375.0 & - & - & 373.7 \\
\hline PET-AP & $224.6 \sim 351.6$ & 81.23 & 294.6 & $351.6 \sim 458.0$ & 14.07 & 3 \\
\hline
\end{tabular}


absorption peaks of $\mathrm{C}-\mathrm{H}$ stretching vibration (2850 3000 $\mathrm{cm}^{-1}$ ), C-H in-plane bending vibration (1350 1490 $\left.\mathrm{cm}^{-1}\right), \quad \mathrm{C}=\mathrm{O}$ stretching vibration (1725 $\mathrm{cm}^{-1}$ ), C-C stretching vibration $\left(1100 \mathrm{~cm}^{-1}\right)$ and $\mathrm{N}_{2} \mathrm{O}$ can be found during the first decomposition stage except the $\mathrm{C}=\mathrm{C}$ stretching vibration peak (1630 1695 $\mathrm{cm}^{-1}$ ). It suggests that the first stage of PET-AP mixture includes the thermal decomposition of PET and the low-temperature decomposition stage of $\mathrm{AP}$, and the oxidation-reduction reactions occurs between the intermediate products of PET and AP.

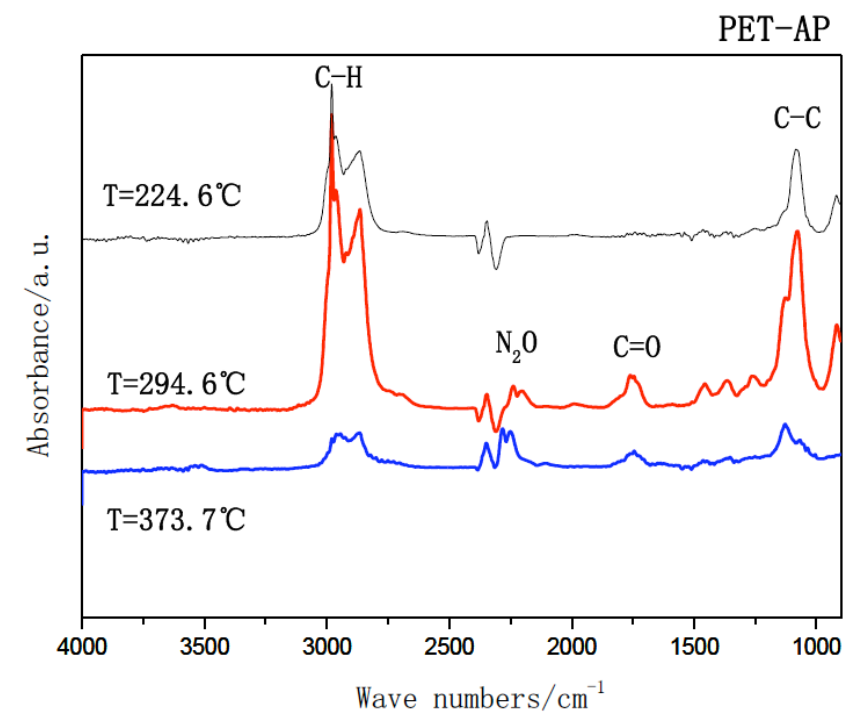

Figure 4: FTIR curves of PET-AP mixture at various temperatures.

Compared with the thermal decomposition behavior of pure PET, the thermal decomposition of PET occurs ahead of $66.8{ }^{\circ} \mathrm{C}$ when it mixes with AP, and the peak temperature of maximum weight-loss rate reduces 80.4 ${ }^{\circ} \mathrm{C}$. It suggests that AP can promote the thermal decomposition of PET significantly. It was reported that the oxidation decomposition of PET is more likely to occur than the pure endothermic pyrolysis, which means oxidizing substances can promote the thermal decomposition of PET [17]. When PET mixes with AP in a mass ratio of $1: 1$, the intermediate products of $A P$ during the low-temperature decomposition $\left(\mathrm{HClO}_{4}\right.$, $\mathrm{ClO}_{3}, \mathrm{ClO}$, O etc.) are intensive oxidation, which can promote the thermal decomposition reaction of PET.

On the other hand, PET also has obvious effect on the thermal decomposition of AP. Although the peak temperatures of two decomposition stages about AP has no great changes, the weight loss ratio of the two stages increases from about 3:7 to about 2:1. Firstly the oxidation-reduction reactions between the intermediate products of $\mathrm{PET}$ and $\mathrm{AP}$ consume a certain amount of $\mathrm{HClO}_{4}$, making a greater degree of the low-temperature decomposition of AP to the right. Secondly a lot of heat is released by the thermal decomposition of PET, making more adsorbed intermediate products desorb and move into the gas phase, then the porous structure of the surface become more prominent on the solid phase. Therefore, PET can promote the low-temperature decomposition of AP significantly.

The characteristic absorption peaks during the first stage still exist during the second stage, but the intensity of the peaks decreased significantly. It suggests that the second stage mainly includes the high-temperature decomposition of AP, accompanied by a small fraction of the decomposition of PET. Compared with the high-temperature decomposition stage of pure AP, the maximum weight loss peak temperature of this stage is ahead of $9^{\circ} \mathrm{C}$, indicating that a small amount of PET still is decomposed at this stage, and it promotes the decomposition of AP.

As we know, $\mathrm{N}_{2} \mathrm{O}$ is the main gas product during the thermal decomposition process of AP, and the infrared absorption intensity changes of $\mathrm{N}_{2} \mathrm{O}$ can be regarded as a sign in the degree of $\mathrm{NH}_{3}$ oxidation reaction. Figure $\mathbf{5}$ shows the infrared absorption intensity curves of $\mathrm{N}_{2} \mathrm{O}$ during the thermal decomposition process of AP, HTPB-AP mixture, PET-AP mixture. The infrared absorption intensity curve of $\mathrm{N}_{2} \mathrm{O}$ during the thermal decomposition process of HTPB-AP mixture is similar with pure AP. Two peaks appear at about $300^{\circ} \mathrm{C}$ and $380^{\circ} \mathrm{C}$ on both curves respectively, and the peak on the curve of HTPB-AP mixture is more acute. But the curve of PET-AP mixture is gentler, indicating that PET can make the redox reaction rate of AP smoother than

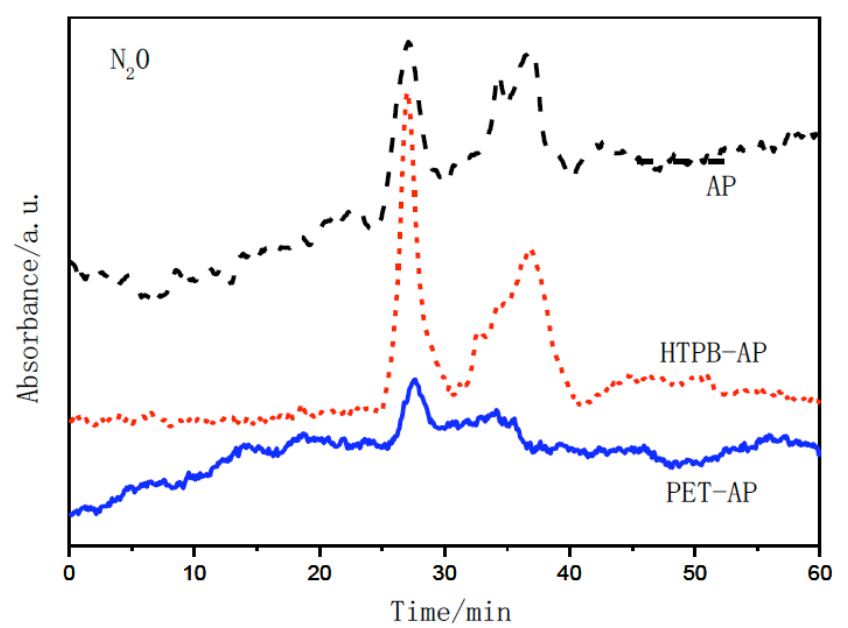

Figure 5: Infrared absorption intensity curves of $\mathrm{N}_{2} \mathrm{O}$. 
$\mathrm{HTPB}$, as well as the release of the gas product $\mathrm{N}_{2} \mathrm{O}$. It may be because PET decomposes into short segments early under the catalysis of the AP, and the oxidationreduction reactions between the intermediate products of PET and AP consume a certain amount of $\mathrm{HClO}_{4}$, so that less $\mathrm{NH}_{3}$ can be oxidized by less $\mathrm{HClO}_{4}$.

\subsection{DSC Analysis}

Figure 6 shows the DSC curves during the thermal decomposition of AP, HTPB, HTPB-AP mixture, and the relevant characteristic parameters are listed in Table 3. It all appears an endothermic peak at $246{ }^{\circ} \mathrm{C}$ on the curves of AP and HTPB-AP mixture, which is the crystal transition peak of AP.

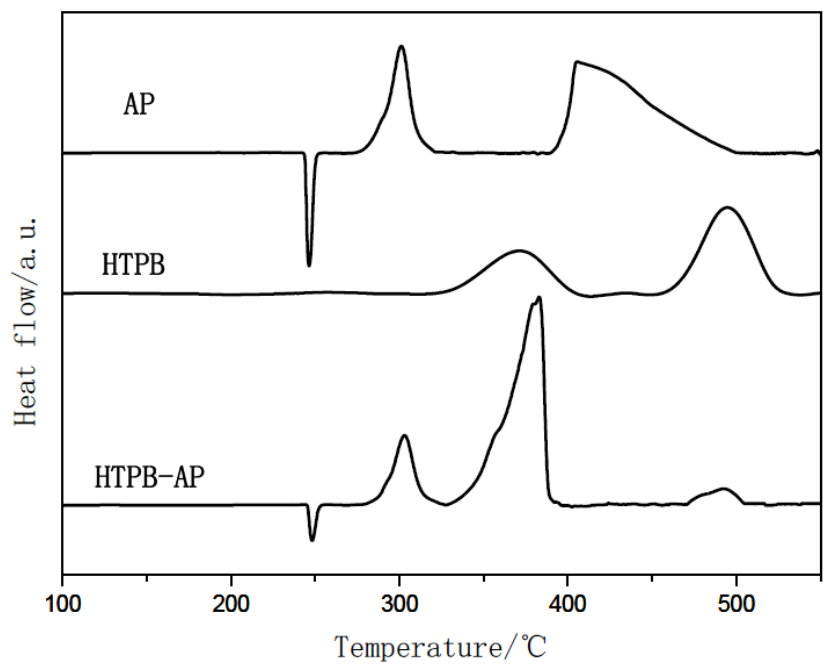

Figure 6: DSC curves of AP, HTPB and HTPB-AP mixture.

When HTPB mixes with AP crystals in a mass ratio of $1: 1$, the total heat release $\left(1080 \mathrm{~J} \cdot \mathrm{g}^{-1}\right)$ is close to the average of AP $\left(1119.3 \mathrm{~J} \cdot \mathrm{g}^{-1}\right)$ and HTPB $\left(831.6 \mathrm{~J} \cdot \mathrm{g}^{-1}\right)$. It suggests that there is no obvious chemical reaction between HTPB and AP in the heating process of HTPB-AP mixture. According to the TG-FTIR analysis above, the heat release during the second decomposition stage of HTPB-AP mixture is supposed to be close the average of $Q_{2}(A P)$ and $Q_{1}(H T P B)$, but it increases greatly, and the heat release of the third stage is much less than the half of $Q_{2}(H T P B)$. This may be because large quantities of heat is released by AP at high-temperature decomposition stage, promoting the cross-linking and cyclization reactions of HTPB prepolymer, so that the degree of cross linking and cyclization reactions increases greatly. But the cracking reaction of cross-linked and cyclic macromolecules will occur at the third stage, which need to absorb more energy due to more chemical bonds.

Figure 7 shows the DSC curves during the thermal decomposition of AP, PET, PET-AP, and the relevant characteristic parameters are listed in Table 4. It also appears an endothermic crystal transition peak at 246 ${ }^{\circ} \mathrm{C}$ on the curves of PET-AP mixture.

When PET mixes with AP crystals according to mass ratio of $1: 1$, the total heat release $\left(997.3 \mathrm{~J} \cdot \mathrm{g}^{-1}\right)$ is between that of AP $\left(1119.3 \mathrm{~J} \cdot \mathrm{g}^{-1}\right)$ and PET (194.8 $\left.\mathrm{J} \cdot \mathrm{g}^{-1}\right)$, and much higher than the average of them. It suggests that some new redox reactions between the intermediate products of PET and AP occur in the heating process of PET-AP mixture.

The heat release of PET-AP mixture is much milder than pure AP and HTPB-AP mixture at each stages of thermal decomposition. Especially in the heating process of HTPB-AP mixture, the heat release amount at the second stage accounts $78.6 \%$ of the total, and it is four times more than that at the first stage, which has negative effect on the cook-off response of the propellant. As we know, when the propellant is under a condition of cook-off, if a lot of heat is released in a short time and cannot be transmit out because the propellant is a poor conductor of heat, it is likely to form the high temperature hot-spot, and cause the overall ignition of propellant, thus generating the explosion or detonation.

\subsection{SEM}

In order to analysis the influence of two binders on AP low-temperature decomposition stage further, the surface morphology of AP and two mixtures before and after the low-temperature decomposition stage were studied by SEM. Figure $\mathbf{8}$ shows the surface

Table 3: DSC Characteristic Values of AP, HTPB and HTPB-AP Mixture

\begin{tabular}{|c|c|c|c|c|c|c|}
\hline \multirow{2}{*}{ Samples } & \multicolumn{2}{|c|}{ First stage } & \multicolumn{2}{c|}{ Second stage } & \multicolumn{2}{c|}{ Third stage } \\
\cline { 2 - 7 } & $\mathbf{T}_{\mathbf{p} 1} /{ }^{\circ} \mathbf{C}$ & $\mathbf{Q}_{\mathbf{1}} / \mathbf{J} \cdot \mathbf{g}^{-1}$ & $\mathbf{T}_{\mathbf{p} 2} /{ }^{\circ} \mathbf{C}$ & $\mathbf{Q}_{\mathbf{2}} / \mathbf{J} \cdot \mathbf{g}^{-1}$ & $\mathbf{T}_{\mathbf{p} 3} /{ }^{\circ} \mathbf{C}$ & $\mathbf{Q}_{3} / \mathbf{J} \cdot \mathbf{g}^{-1}$ \\
\hline \hline AP & 301.1 & 284.3 & 405.6 & 835.0 & - & - \\
\hline HTPB & 371.3 & 325.6 & 494.7 & 506.0 & - \\
\hline HTPB-AP & 303.0 & 177.8 & 382.8 & 848.4 & 492.5 & 53.8 \\
\hline
\end{tabular}




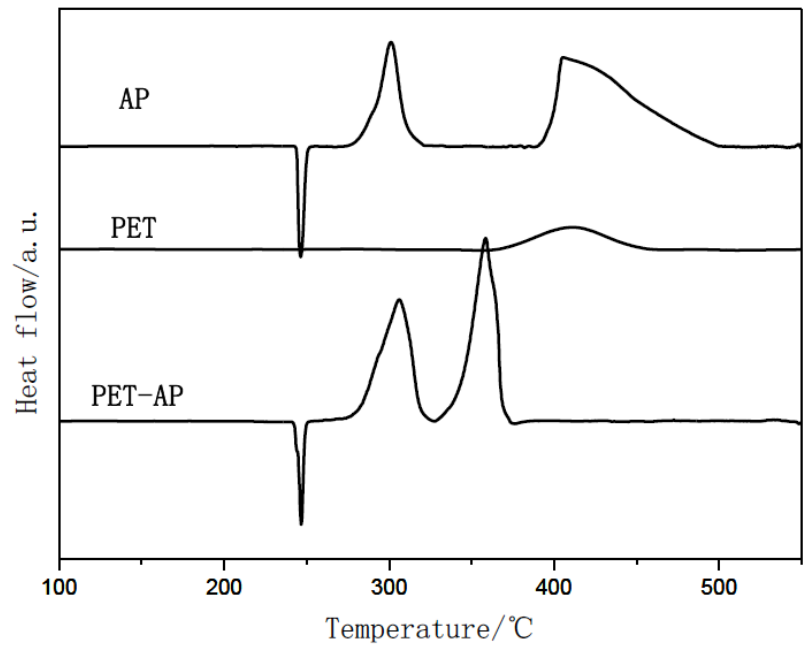

Figure 7: DSC curves of AP, PET, PET-AP mixture.

morphology pictures of AP before and after the first stage under the different magnification. The changes of surface morphology can be observed obviously, and the smooth surface becomes the porous structure after heating to $310^{\circ} \mathrm{C}$.

Figure 9 shows the surface morphology pictures of two mixtures after the low-temperature decomposition stage under the different magnification. Firstly, AP particles and the intermediate products of HTPB are separate obviously, while these of PET are adhere to the particles partly. Secondly, the porous structures of PET-AP mixture are more obvious and significant than HTPB-AP mixture, suggesting that the decomposition degree of solid particles in HTPB-AP mixture is less than PET-AP mixture. PET can decompose ahead of time under the catalysis of $A P$, and react with the intermediate products of $\mathrm{AP}$, promoting the lowtemperature decomposition of AP, but HTPB has no such interaction with AP obviously.

Table 4: DSC Characteristic Values of AP, PET, PET-AP Mixture

\begin{tabular}{|c|c|c|c|c|}
\hline \multirow{2}{*}{ Samples } & \multicolumn{2}{|c|}{ Frist Stage } & \multicolumn{2}{c|}{ Second Stage } \\
\cline { 2 - 5 } & $\mathbf{T}_{\mathbf{p} 1} /{ }^{\circ} \mathbf{C}$ & $\mathbf{Q}_{\mathbf{1}} / \mathbf{J} \cdot \mathbf{g}^{-1}$ & $\mathbf{T}_{\mathbf{p} 2}{ }^{\circ} \mathbf{C}$ & $\mathbf{Q}_{\mathbf{2}} / \mathbf{J} \cdot \mathbf{g}^{-1}$ \\
\hline \hline AP & 301.1 & 284.3 & 405.6 & 835.0 \\
\hline PET & 411.2 & 194.8 & - & - \\
\hline PET-AP & 306.1 & 453.1 & 358.6 & 544.2 \\
\hline
\end{tabular}

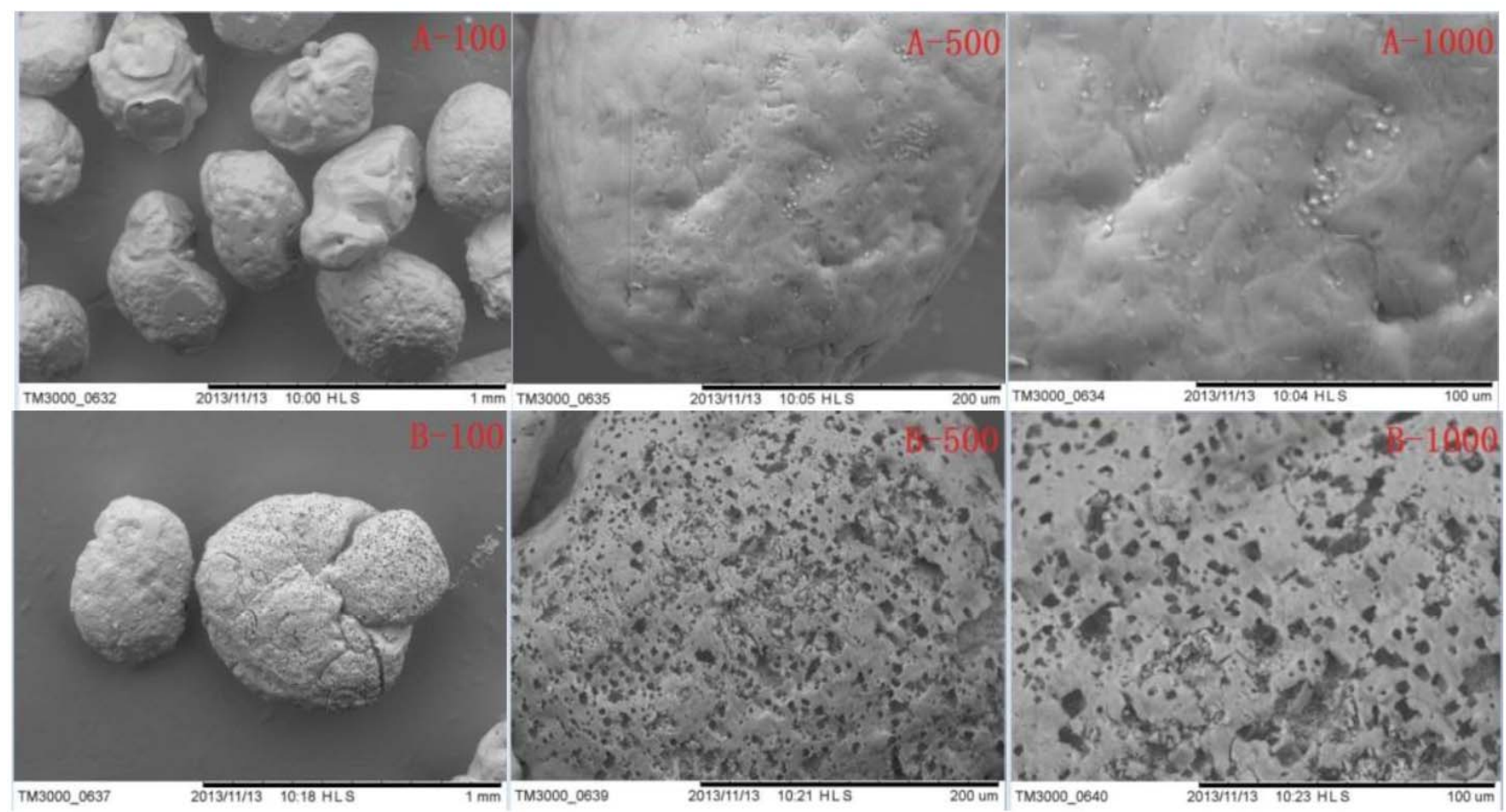

Figure 8: The surface figure of AP before and after the first decomposition stage.

(A-before decomposition, B-after decomposition, the number is magnification times). 


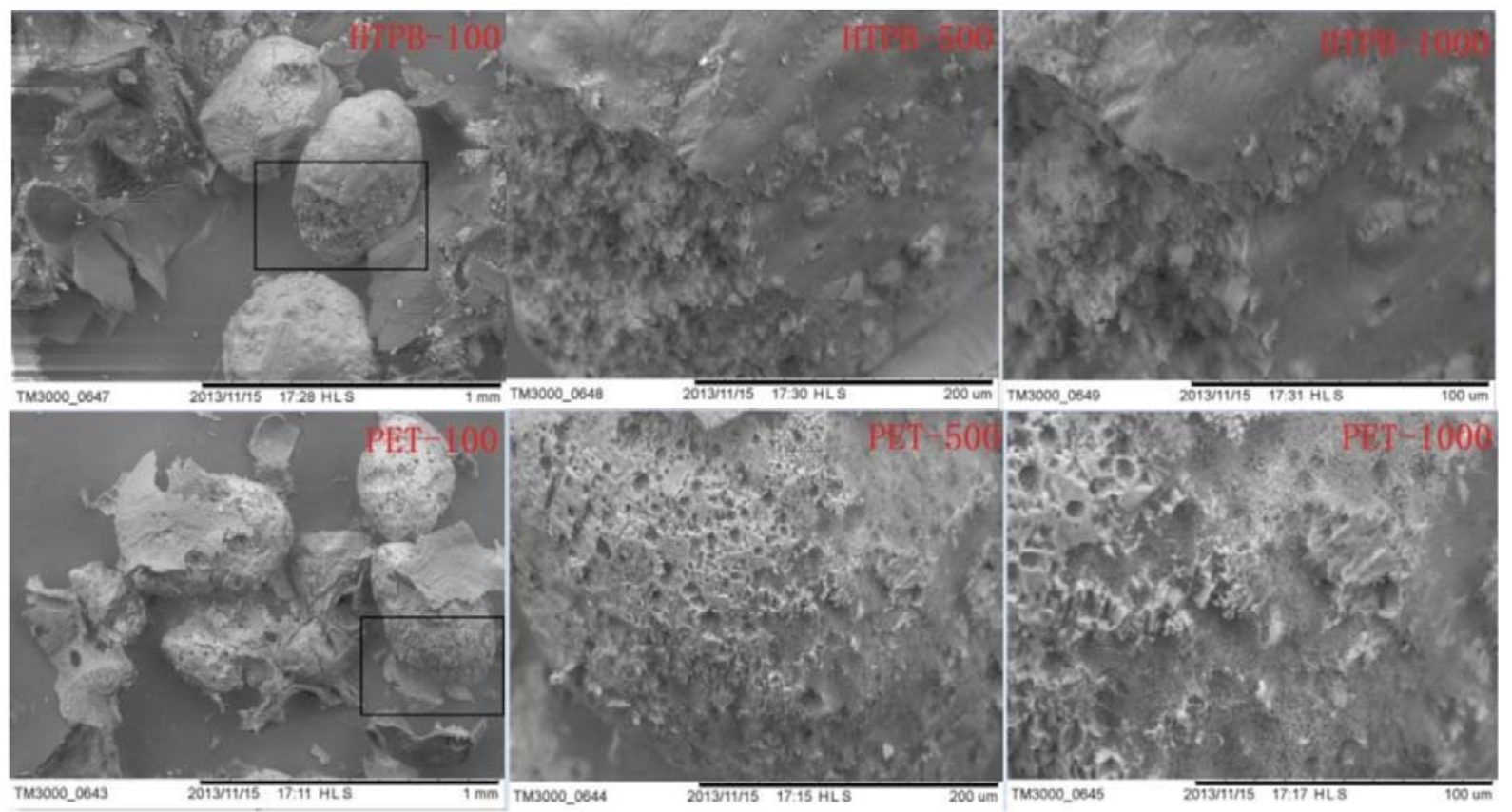

Figure 9: The surface figure of HTPB-AP mixture and PET-AP mixture after the first decomposition stage.

\section{CONCLUSIONS}

When HTPB mixes with AP particles, the thermal decomposition behavior do not change significantly, which means HTPB prepolymer has no obvious effect on the thermal decomposition characteristics of AP. But the opposite result can be found when PET mixes with AP particles. PET prepolymer can decompose in advance under the catalysis of AP crystal surface activity center and strong oxidation products. On the other hand, the decomposition of PET promotes the low-temperature decomposition of $\mathrm{AP}$, making the heat release increase significantly. The heat release and output of gaseous products during the thermal decomposition of PET-AP mixture is milder, which is more conducive to the insensitive performance of the propellant. But on the contrary, the heat release of HTPB-AP mixture mainly concentrates on the hightemperature decomposition of AP.

\section{REFERENCES}

[1] Yan-Ping W, Xiao-Yun X, Jun-Wu Z. Catalytic Activity of Nanometer -Sized $\mathrm{CuO} / \mathrm{Fe}_{2} \mathrm{O}_{3}$ on Thermal Decompositon of AP and Combustion of AP-Based Propellant. Combustion Science and Technology 2011; 154: 162-2.

[2] Xue-Zhong F, Ji-Zhen L, Xiao-Long F, Han W. Thermal Decompositions of Ammonium Perchlorate of Various Granularities. Actachimicasinica 2009; 39: 44-1.

[3] Sheng-Liang $X$, Lan L, Wei H, Zhi-Ping $H$. Correlation Investigation on Thermal Decomposition of PET Binder, Its Elastomer and Propellants. Chemical Propellants \& Polymeric Materials 2011; 49: 54-5.
[4] La-Ying Z, Shu-Yun H, Zi-Ru L. Interaction of PET with some high energy oxidizers by thermal analysis. J Solid Rocket Tech 2010; 191: 195-2. http://www.doc88.com/p9062737327259.html

[5] Xue-Yun G, Yu-Peng G, Li-Bo W, Peng-Fei G. MicrowaveAssisted Synthesis and Catalytic Performance of Hierarchical $\mathrm{Cu}_{2} \mathrm{O}$ Nanostructures. NANO 2013; 11: 15-8. http://dx.doi.org/10.1142/S1793292013500471

[6] Jian-Xun L, Zuo-Shan W, Wei J. Preparation of $\mathrm{Co}_{3} \mathrm{O}_{4} / \mathrm{CNTS}$ composites and their catalytic effects on the thermal decomposition of AP and AP/HTPB propellant. Rare Metal Materials And Engineering 2007; 649: 653-3.

[7] Yi-Fu Z, Nan-Nan W, Yu-Ting H. Fabrication and catalytic activity of ultra-long $\mathrm{V}_{2} \mathrm{O}_{5}$ nanowires on the therma decomposition of ammonium perchlorate. Ceramics International 2014; 11393: 11398-7. http://dx.doi.org/10.1016/i.ceramint.2014.03.026

[8] Gen T, Shou-Qin T, Zhao-Xia Z. ZnO Micro/Nanocrystals with Tunable Exposed (0001) Facets for Enhanced Catalytic Activity on the Thermal Decomposition of Ammonium Perchlorate. J Phys Chem C 2014; 11833: 11843-22.

[9] Lin-Lin L, Guo-Qiang H, Ying-Hong W. Effect of catocene on the thermal decomposition of ammonium perchlorate and octogen. J Therm Analysis Calorimetry 2014; 621: 628-2. http://dx.doi.org/10.1007/s10973-014-3792-5

[10] Ji-Bin Z, Heng-Dong L, Cai-Xia L. Ferrocene-based sulfonyldihydropyrazole derivatives: Synthesis, structure, electrochemistry and effect on thermal decomposition of $\mathrm{NH}_{4} \mathrm{ClO}_{4}$. J Mole Struc 2014; 112: 119-5.

[11] Qing-Jie J, Yan-Li Z, Jia-Chao X. Thermal decomposition of RDX/AP by TG-DSC-MS-FTIR. J Therm Analysis Calorimetry 2014; 1125: 1131-3.

http://dx.doi.org/10.1007/s10973-013-3621-2

[12] Zi-Ru L, Cui-Mei Y, Yang-Hui K, Ffeng-Qi Z, Yang L, Hu Z. Interaction of ammonium perchlorate with $\mathrm{HMX}$ and RDX during decomposition. J Propu Tech 2000; 70: 73-6.

[13] Zi-Run L, Zhen-Hao S, Cui-Mei Y, Feng-Qi Z. Investigation on thermal decomposition of mixed systems of AP with RDX and HMX by DSC-TG-FTIR. Chinese J Explosive Propellants 2007; 57: 61-5. 
[14] Yan-Li Z, Zhi-Xia X, Qing-Jie J. Effects of Aluminum on Thermal Decomposition of Hexogen/Ammonium Perchlorate. Chemical Research of Chinese Universities 2014; 666: 6714.

http://dx.doi.org/10.1007/s40242-014-4016-z

[15] Yan-Li Z, Qing-Jie J, Hao H, Hui R. Effect of Aluminum Particle Size on Thermal Decomposition of AP. Chemical Research of Chinese Universities 2013; 662: 667-3.
[16] Ji-Zhen L, Xiao-Long F, Xiao-Gang L. Correlation Between Burning Rate and Thermal Decomposition ofAP/AI-CMDB Propellant. Acta Armamentarii 2010; 1351: 1356-10.

[17] Juan-Ji L. Thermal pyrolysis Characteristics of Ethylene oxid/Tetrahydrofuran (EO/THF) Copolyether Urethane. Chang Sha: National University of Defense Technology 2008. 